\title{
Trends in outpatient cataract surgery in the Islamic Republic of Iran, 2006-2010
}

\author{
H. Hashemi ${ }^{1}$, A. Fotouhi ${ }^{2}$, F. Rezvan ${ }^{3}$, H. Gilasi ${ }^{4}$, S. Asgari ${ }^{3}$, S. Mohazzab-Torabi ${ }^{1}$, K. Etemad ${ }^{5}$, A. Yekta $^{6}$,
} M. Khabazkhoob



ABSTRACT This study aimed to determine the trends in outpatient cataract surgery and its determinants in the Islamic Republic of Iran between 2006 and 2010. In this cross-sectional study, 106 cataract surgery centres were selected in all provinces by multistage randomized cluster sampling. The number of centres in each province was determined from the number of cataract operations and the number of patient charts examined in each centre was proportionate to the number of cataract operations in that centre. The prevalence of outpatient surgery increased from $46.0 \%(95 \% \mathrm{Cl}, 35.3-56.8)$ in 2006 to $51.4 \%(95 \% \mathrm{Cl}, 40.2-62.7)$ in $2010(\mathrm{P}=0.549)$. Patients stayed in hospital for more than one night after $10.5 \%(95 \% \mathrm{Cl}, 6.9-14.1)$ of operations. Use of phacoemulsification and topical anaesthesia increased the prevalence of outpatient surgery and decreased intraoperative complications. Although outpatient cataract surgery increased by $11.7 \%$, use of methods such as phacoemulsification is not widespread, and more attention should be paid to the barriers to outpatient cataract surgery in the Islamic Republic of Iran.

\section{Tendances de la chirurgie ambulatoire de la cataracte en République islamique d'Iran, 2006-2010}

RÉSUMÉ La présente étude avait pour objectif de déterminer les tendances de la chirurgie de la cataracte en ambulatoire et ses déterminants en République islamique d'Iran entre 2006 et 2010. Dans cette étude transversale, 106 centres de chirurgie de la cataracte ont été sélectionnés dans toutes les provinces par échantillonnage aléatoire en grappes à plusieurs degrés. Le nombre de centres dans chaque province a été déterminé sur la base du nombre d'opérations de la cataracte et le nombre de dossiers de patients examinés dans chaque centre était proportionnel au nombre de chirurgies de la cataracte pratiquées dans ce centre. La prévalence des chirurgies de la cataracte est passée de $46 \%$ (IC à $95 \%, 35,3-56,8)$ en 2006 à 51,4\% (IC à $95 \%, 40-62,7)$ en 2010 ( $p=0,549)$. Les patients sont restés plus d'une nuit à l'hôpital après 10,5\% (IC à 95\%, 6,9-14,1) des opérations. Le recours à la phaco-émulsification et l'anesthésie topique faisait augmenter la prévalence de la chirurgie ambulatoire et réduisait les complications intra-opératoires. Bien que la chirurgie de la cataracte en ambulatoire ait augmenté de $11,7 \%$, I'utilisation de méthodes telles que la phaco-émusification n'est pas répandue, et davantage d'attention devrait être apportée aux obstacles qui s'opposent à la chirurgie de la cataracte en ambulatoire en République islamique d'Iran.

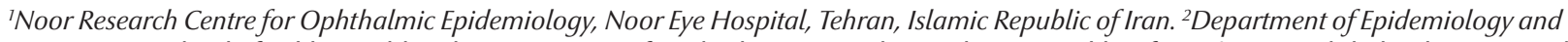
Biostatistics, School of Public Health, Tehran University of Medical Sciences, Tehran, Islamic Republic of Iran. ${ }^{3}$ Noor Ophthalmology Research Centre, Noor Eye Hospital, Tehran, Islamic Republic of Iran. ${ }^{4}$ Department of Public Health and Biostatistics, Faculty of Health, Kashan University of Medical Sciences, Kashan, Islamic Republic of Iran. ${ }^{5}$ Department of Epidemiology, Faculty of Public Health, Shahid Beheshti University of Medical Sciences, Tehran, Islamic Republic of Iran. ${ }^{6}$ Department of Optometry, School of Sciences, Mashhad University of Medical Sciences, Mashhad, Islamic Republic of Iran. 'Department of Medical Surgical Nursing, School of Nursing and Midwifery, Shahid Beheshti University of Medical Sciences, Tehran, Islamic Republic of Iran (Correspondence to: khabazkhoob@yahoo.com).

Received: 25/11/15; accepted: 03/07/16 


\section{Introduction}

The latest report from WHO (1) indicated that about 20 million people worldwide are blind as a result of cataract, corresponding to half of all cases of blindness (2). The high prevalence of cataracts in people over the age of 50 makes their removal one of the most prevalent operations, imposing heavy costs on countries (3), due mainly to the type of lens and surgical and hospitalization costs (4). Outpatient cataract surgery in many centres around the world has resulted in an increase in the rate of surgery for this condition, and, because there is no hospitalization, the waiting time has decreased (5). Thus, outpatient cataract surgery reduces the cost of the operation by $20 \%(6,7)$. It has been shown that US\$ 33.6 million could be saved annually in Spain and US\$270 per surgery in England if 80\% of cataract operations were performed on an outpatient basis $(7,8)$. Although the cost of cataract surgery differs by country, eliminating hospitalization after surgery has many advantages for governments and patients. Identification of the factors that contribute to an increase in outpatient cataract surgery could increase its use. One of the most important factors is use of the phacoemulsification method $(9,10)$.

A recent report by our group showed a substantial increase in the cataract surgery rate in our country over 10 years (11). Therefore, the costs of hospitalization, ophthalmologists' fees, consumables and indirect costs have also increased. We performed the present study to evaluate the prevalence of and trends in outpatient cataract surgery and its determinants, in order to find ways to reduce the costs.

\section{Methods}

This cross-sectional study was performed between March 2011 and May 2012. The target population was patients who underwent cataract surgery in centres in Iran between 2006 and 2010.

\section{Sampling}

The methods used have been described in detail elsewhere (12); a summary is given here. According to the Iranian Ministry of Health, there are 272 cataract surgery centres in the country, of which 35 were not included in the study because fewer than 100 cataract operations are performed per year. Of the remaining 237 centres, 106 were selected by multistage randomized cluster sampling. The number of centres in each province was determined according to the number of cataract operations in that province, and the number of charts of patients who underwent cataract surgery was proportionate to the number of operations in the centre.

Ten data collectors were trained to sample patient charts after they had established the necessary coordination with the archiving department. They extracted information on the underlying disease, the type of cataract, the method of surgery and the type of lens and also identified intraoperative complications. They collected information on the age and sex of the patient, date of surgery, discharge date and the name of the surgeon. The duration of hospitalization was calculated as the interval between admission and discharge. To ensure consistency, five charts were given to 10 data collectors to evaluate; in cases of disagreement, the opinion of an ophthalmologist was sought.

\section{Statistical analysis}

The prevalence of outpatient surgery and hospitalization for more than one night is given as a percentage with $95 \%$ confidence intervals (CIs) and standard errors, with account taken of the effect of cluster sampling. The $\chi^{2}$ test was used to examine the effects of variables. The relation between outpatient surgery and hospitalization for more than one night was examined in simple and multiple logistic regression models. All analyses were done with STATA software version 11 .

\section{Results}

We evaluated 26727 charts from 106 centres. After exclusion of charts that were incomplete, 23020 charts were analysed. Males represented $48.1 \%$ of the patients; $0.4 \%$ of the patients were aged $\leq 10$ years, $3.7 \%$ were aged $11-40$ years, $7.6 \%$ were aged $41-50$ years, $17.9 \%$ were aged $51-60$ years, $28.3 \%$ were aged $61-70$ years, $30.8 \%$ were aged $71-80$ years, and $11.2 \%$ were aged $>80$ years. Of all the cataract operations, 49.9\% (95\% CI, 39.5-60.4) were performed in an outpatient setting. The prevalence of outpatient cataract surgery increased by $11.7 \%$ between 2006 and 2010, from $46.0 \%$ (95\% CI, $35.3-56.8$ ) in 2006 to $51.4 \%$ (95\% CI, $40.2-62.7)$ in 2010. No significant difference in the prevalence of outpatient cataract surgery was found by year $\left(\chi^{2}\right.$ $=31.27, P=0.549)$, and no significant difference was found between males $(50.3 \%)$ and females $(49.6 \%)\left(\chi^{2}=\right.$ $0.977, P=0.594)$. Table 1 shows that the prevalence of outpatient cataract surgery differed significantly according to age $\left(\chi^{2}=38.46, P<0.001\right)$. The lowest percentage was observed in patients aged $<10$ years.

The prevalence of outpatient cataract surgery did not differ significantly by season $\left(\chi^{2}=6.79, P=0.499\right)$ (Table $1)$. Most outpatient operations were performed by the phacoemulsification method (52.5\%; 41.8-63.2) and the fewest by the extracapsular method $\left(\chi^{2}\right.$ $=5.3 .72 ; P<0.001)$.

Intraoperative complications occurred in $31.6 \%$ (95\% CI, 18.6-44.6) of operations, and $50.7 \%$ (95\% CI, 40.1-61.3) were complication-free. The odds for complications were 2.22 (95\% CI, 1.39-3.54) times higher in inpatient surgery $(P<0.001)$. Most of the outpatient operations (75.9\%) were 


\begin{tabular}{|c|c|c|}
\hline & Outpatient & Hospitalization $>1$ night \\
\hline & $\%(95 \% \mathrm{Cl})$ & $\%(95 \% \mathrm{Cl})$ \\
\hline Total & $49.9(39.5-60.4)$ & $10.5(6.9-14.1)$ \\
\hline \multicolumn{3}{|l|}{ Year } \\
\hline 2006 & $46.0(35.3-56.8)$ & $11.0(6.0-15.9)$ \\
\hline 2007 & $50.4(38.3-62.5)$ & $10.0(6.0-14.0)$ \\
\hline 2008 & $49.9(38.5-61.3)$ & $12.2(7.0-17.5)$ \\
\hline 2009 & $51.2(39.6-62.7)$ & $10.0(5.7-14.3)$ \\
\hline 2010 & $51.4(40.2-62.7)$ & $9.3(5.3-13.4)$ \\
\hline \multicolumn{3}{|l|}{ Gender } \\
\hline Male & $50.3(39.9-60.7)$ & $10.4(6.8-14.1)$ \\
\hline Female & $49.6(39.0-60.3)$ & $10.4(6.8-14.0)$ \\
\hline \multicolumn{3}{|l|}{ Age } \\
\hline$\leq 10$ & $44.7(32.3-57.1)$ & $21.3(8.0-34.6)$ \\
\hline $11-40$ & $47.0(35.4-58.5)$ & $13.8(9.2-18.4)$ \\
\hline $41-50$ & $53.9(38.0-69.9)$ & $9.6(6.4-12.8)$ \\
\hline $51-60$ & $46.7(36.0-57.4)$ & $9.0(5.9-12.0)$ \\
\hline $61-70$ & $50.7(40.0-61.4)$ & $9.5(6.0-12.9)$ \\
\hline $71-80$ & $51.0(40.3-61.7)$ & $11.2(6.9-15.4)$ \\
\hline$>80$ & $48.8(37.3-60.3)$ & $12.8(7.6-18.0)$ \\
\hline \multicolumn{3}{|l|}{ Season } \\
\hline Spring & $50.8(40.0-61.7)$ & $10.8(6.8-14.9)$ \\
\hline Summer & $49.6(38.9-60.2)$ & $10.0(6.5-13.6)$ \\
\hline Autumn & $48.7(38.2-59.1)$ & $11.1(7.3-14.9)$ \\
\hline Winter & $50.6(40.0-61.2)$ & $10.1(6.5-13.7)$ \\
\hline \multicolumn{3}{|l|}{ Type of surgery } \\
\hline Intracapsular & $43.4(7.5-79.2)$ & $26.5(8.3-44.7)$ \\
\hline Extracapsular & $23.0(8.8-37.3)$ & $27.1(12.9-41.3)$ \\
\hline Phacoemulsification & $52.5(41.8-63.2)$ & $8.5(5.4-11.6)$ \\
\hline Lensectomy & $37.4(16.3-58.5)$ & $39.8(19.5-60.2)$ \\
\hline
\end{tabular}

$\mathrm{Cl}=$ confidence interval.

performed under topical anaesthesia and $40.7 \%$ of inpatient operations under general anaesthesia $(P<0.001)$.

The duration of hospital stay was more than one night after 10.5\% (95\% CI, 6.9-14.1) of operations. A hospital stay of more than one night showed a U-shaped relation with age, with the highest prevalence for patients aged < 10 years, followed by a decrease and then an increase after the age of 70 years. As shown in Table 1, 39.8\% (95\% CI, 19.5-60.2) of patients who underwent lensectomy and $8.5 \%$ of patients who underwent phacoemulsification were hospitalized for more than one night, the difference being significant $(P<$ $0.001)$. Of the patients hospitalized for more than one night, $41.3 \%$ (95\% CI, 26.3-56.2) had intraoperative complications and 9.3\% (95\% CI, 6.0-12.5) had no complications. The odds ratio for hospitalization was significantly higher after cataract surgery with intraoperative complications (1.93; 95\% CI, 3.9-12.0). More than one night of hospitalization was required for $14.7 \%$ of operations performed by residents and $10.4 \%$ of operations performed by surgeons other than residents $(P<$ $0.001)$. Two multiple logistic regression models were used to evaluate the relations between outpatient surgery, hospitalization for more than one night and other variables (Table 2).

\section{Discussion}

About half of all cataract operations were performed in an outpatient setting during the 5 years of the study, with no significant change, the prevalence increasing by only $11.7 \%$. Few studies have been conducted in other countries; Mojon-Azzi et al. (13) reported a wide range in the prevalence of outpatient 
cataract surgery in 10 countries, from 0\% in Australia to 100\% in Denmark; however, apart from Australia, where all operations are performed in hospital, and Greece, where only $41 \%$ of cataract operations are performed in an outpatient setting, the rate was $>50 \%$. In the Netherlands and Sweden, more than 90\% of operations were performed in an outpatient setting. We had expected that more than $80 \%$ of the operations in the Islamic Republic of Iran would be performed in an outpatient setting in view of the recent increase in use of phacoemulsification and the strong correlation between use of this method and outpatient surgery. This study shows that a number of factors other than the type of surgery decrease the duration of hospitalization.

The duration of hospitalization affects waiting time and costs. The Government of China has decreased the rate of blindness due to cataract dramatically by increasing outpatient cataract surgery, and not only surgeons but also governments are interested in greater use of outpatient cataract surgery to reduce costs $(14,15)$. Leong et al. (8) showed that hospitalization for cataract surgery was significantly higher in spring and autumn, whereas we found no significant difference in the rate of outpatient cataract surgery by season, perhaps due to the distribution of facilities in the Islamic Republic of Iran, which has made the operation available throughout the year.
Use of the phacoemulsification method has increased over the past 10 years in many countries, including ours, because it is faster, leads to fewer complications $(5,16,17)$, and satisfies patients (17). In a previous study, we found that the rate of phacoemulsification surgery had increased from $7 \%$ in 2000 to $57 \%$ in 2005, while the rate of extracapsular cataract extraction surgery decreased from $91 \%$ to $41 \%$ over the same period (18) and from $89.1 \%$ to $92 \%$ between 2006 and 2010. Despite a difference in cost of US\$245 between phacoemulsification and intracapsular cataract extraction, phacoemulsification is recommended because of its shortand long-term benefits, including fewer complications and shorter hospital stays (19). The rapid increase in cataract surgery has been associated with a decrease in the duration of hospital stays. In Canada, 50-55 cataract patients were hospitalized per 10000 patients in 1991 and only $1-2$ per 10000 in 2002, at a time when the rate of phacoemulsification surgery increased by 100 times (8). Factors such as reduced costs and faster procedures have decreased the duration of hospital stays (20).

Thus, use of the phacoemulsification model and topical anaesthesia has increased the rate of outpatient cataract surgery, and the rate of intraoperative complications has decreased. Nevertheless, it is important that all conditions be evaluated prior to operation in older individuals with risk factors. Topical anaesthesia is very useful for outpatients and leads to fewer post-surgical complications (21), and previous studies have described the efficacy of topical anaesthesia in outpatient operations, even when performed by residents (22-24). Koolwijk et al. (25) reported that outpatient cataract surgery is easy and safe with topical anaesthesia, with minimal complications. In a 2-year evaluation of 4347 patients, they found that only $0.04 \%$ required intervention during the operation and none required hospitalization. The risk for endophthalmitis increases with topical anaesthesia and the phacoemulsification method (26), however, as seen in 8.7 per 1000 operations versus 1.3 per 1000 operations with retrobulbar anaesthesia (27), a complication that requires hospitalization. Castelle et al. (7) evaluated 1103 patients and found that, despite a significantly higher incidence of complications in outpatient surgery, the long-term complications were similar after outpatient and inpatient surgery. In a study in Spain, Cortinas et al. (28) observed that 499 of 11187 (4.46\%) outpatients operated by phacoemulsification required hospitalization, of whom 460 were hospitalized immediately after surgery. Other studies have reported longer hospitalization after general anaesthesia (29). We found that the rate of hospitalization after surgery was significantly higher when operations were performed by residents, perhaps due to a higher prevalence of more severe complications.

\begin{tabular}{|c|c|c|c|c|}
\hline \multirow[t]{2}{*}{ Variable } & \multicolumn{2}{|c|}{ Outpatient } & \multicolumn{2}{|c|}{ Hospitalization for $>1$ night } \\
\hline & OR $(95 \% \mathrm{Cl})$ & $P$ & OR $(95 \% \mathrm{Cl})$ & $\boldsymbol{P}$ \\
\hline Age (years) & 1.00 & 0.824 & 1.00 & 0.204 \\
\hline Gender (male:female) & $1.02(0.91-1.14)$ & 0.757 & $0.98(0.88-1.09)$ & 0.735 \\
\hline Complications (yes/no) & $5.68(3.24-9.95)$ & $<0.001$ & $0.52(0.36-0.75)$ & 0.001 \\
\hline Phacoemulsification (no/yes) & $0.33(0.16-0.67)$ & 0.003 & $2.60(1.3-5.23)$ & 0.008 \\
\hline Topical anaesthesia (no/yes) & $0.57(0.29-1.12)$ & 0.102 & $4.02(1.87-8.60)$ & $<0.001$ \\
\hline
\end{tabular}

$C l=$ confidence interval; $O R=$ odds ratio. 
Although it has been shown that the quality of operations by residents, especially phacoemulsification surgery, is acceptable $(29,30)$, complications such as vitreous loss (31-33) are more common; therefore, all patients should undergo a complete evaluation before surgery to prevent or reduce the incidence of complications $(34,35)$.

The most important strength of the study was the large sample size obtained by cluster sampling in many centres. Lack of evaluation of factors such as the patients' socio-economic status, outof-pocket expenditure by patients and their families, distance to the eye care facility (access), feedback on willingness and satisfaction, ophthalmologists' views, incentives and disincentives for surgeons and facilities was a limitation of this study. We were therefore unable to identify barriers efficiently. We suggest that researchers use the results of this study to evaluate the indexes of hospitalization after cataract surgery.

In conclusion, this study shows the trends in hospitalization after cataract surgery over 5 years. In general, the percentage of outpatient cataract surgery was relatively low. The absence of complications of surgery and use of phacoemulsification shortened the duration of hospital stay. Other important factors might play a role, and we suggest that larger studies be conducted on economical hospitalization, patient and physician satisfaction and access to services.

Funding: This project was funded by the noncommunicable disease unit of the Ministry of Health, Treatment and Medical Education, Tehran, Islamic Republic of Iran.

Competing interests: None declared.

\section{References}

1. Pascolini D, Mariotti SP. Global estimates of visual impairment: 2010. Br J Ophthalmol. 2012;96:614-8.

2. Javitt JC, Wang F, West SK. Blindness due to cataract: epidemiology and prevention. Annu Rev Public Health. 1996;17:15977.

3. Foster A. Vision 2020: the cataract challenge. Community Eye Health. 2000;13:17-9.

4. Agarwal A, Kumar DA. Cost-effectiveness of cataract surgery. Curr Opin Ophthalmol. 2011;22:15-8.

5. Cillino S, Casuccio A, Di Pace F, Pillitteri F, Cillino G, Lodato G. Day care cataract surgery in central and southern Italy: a multicentric survey. BMC Health Serv Res. 2007;7:16.

6. Fan YP, Boldy D, Bowen D. Comparing patient satisfaction, outcomes and costs between cataract day surgery and inpatient surgery for elderly people. Aust Health Rev. 1997;20:2739.

7. Castells X, Alonso J, Castilla M, Ribó C, Cots F, Antó JM. Outcomes and costs of outpatient and inpatient cataract surgery: a randomised clinical trial. J Clin Epidemiol. 2001;54:23-9.

8. Watts M, Pearce J. Day-case cataract surgery. Br J Ophthalmol. 1988;72:897-9.

9. Leong AM, Crighton EJ, Moineddin R, Mamdani M, Upshur RE. Time series analysis of age related cataract hospitalizations and phacoemulsification. BMC Ophthalmol. 2006;6:2.

10. Lee $S, \operatorname{Tan} D$. Changing trends in cataract surgery in Singapore. Singapore Med J. 1999;40:256-9.

11. Hashemi H, Alipour F, Mehravaran S, Rezvan F, Fotouhi A, Alaedini F. Five year cataract surgical rate in Iran. Optom Vis Sci. 2009;86:890-4.

12. Hashemi H, Fotouhi A, Rezvan F, Etemad K, Gilasi H, Asgari S, et al. Cataract surgical rate in Iran: 2006 to 2010. Optom Vis Sci. 2014;91:1355-9.

13. Mojon-Azzi SM, Mojon DS. Waiting times for cataract surgery in ten European countries: an analysis using data from the SHARE survey. Br J Ophthalmol. 2007;91:282-6.

14. Boone WB, Castoria Seymore J. Outpatient cataract and intraocular lens surgery. J Natl Med Assoc. 1984;76:1201.

15. Yan X, Congdon N, He M. Prevention of cataract blindness in rural China. Asia-Pac J Ophthalmol. 2012;1:69-71.

16. Zemba M, Filip M, Bobeico V, Andrei S, Anton O. [Cataract surgery in Romania - 2003]. Oftalmologia (Bucharest). 2003;48:64-9.
17. Huang W, Huang G, Wang D, Yin Q, Foster PJ, He M. Outcomes of cataract surgery in urban southern China: the Liwan Eye Study. Invest Ophthalmol Vis Sci. 2011;52:16-20.

18. Hashemi H, Alipour F, Mehravaran S, Rezvan F, Alaeddini F, Fotouhi A. Six year trend in cataract surgical techniques in Iran. Middle East Afr J Ophthalmol. 2011;18:150.

19. Fedorowicz Z, Lawrence D, Gutierrez P. Day care versus in-patient surgery for age-related cataract. Cochrane Database Syst Rev. 2005;CD004242:pub2.

20. Semmens JB, Li J, Morlet N, Ng J. Trends in cataract surgery and postoperative endophthalmitis in Western Australia (1980-1998): the Endophthalmitis Population Study of Western Australia. Clin Experiment Ophthalmol. 2003;31:213-9.

21. White PF, White LM, Monk T, Jakobsson J, Raeder J, Mulroy MF, et al. Perioperative care for the older outpatient undergoing ambulatory surgery. Anesth Analg. 2012;114:1190-215.

22. Irle S, Lückefahr M, Tomalla M. [Topical anaesthesia as routine procedure in cataract surgery - evaluation of pain and complications in 1010 cases]. Klin Monatsbl Augenheilkd. $2005 ; 222: 36-40$

23. Sauder G, Jonas JB. Topical versus peribulbar anaesthesia for cataract surgery. Acta Ophthalmol Scand. 2003;81:596-9.

24. Ünal M, Yücel I, Sarıcı A, Artunay Ö, Devranoğlu K, Akar Y, et al. Phacoemulsification with topical anesthesia: resident experience. J Cataract Refract Surg. 2006;32:1361-5.

25. Koolwijk J, Fick M, Selles C, Turgut G, Noordergraaf JI, Tukkers FS, et al. Outpatient cataract surgery: incident and procedural risk analysis do not support current clinical ophthalmology guidelines. Ophthalmology. 2015;122:281-7.

26. Wong TY, Chee SP. The epidemiology of acute endophthalmitis after cataract surgery in an Asian population. Ophthalmology. 2004;111:699-705.

27. Garcia-Arumi J, Fonollosa A, Sararols L, Fina F, Martínez-Castillo $\mathrm{V}$, Boixadera $\mathrm{A}$, et al. Topical anesthesia: possible risk factor for endophthalmitis after cataract extraction. J Cataract Refract Surg. 2007;33:989-92.

28. Cortinas M, Martinez LL, Granados JM, Puerto N, Mendez M, Lizan-Garcia M, et al. [Results of an outpatient major surgery programme in ophthalmology]. Arch Soc Esp Oftalmol. 2006;81:701-8.

29. Groegaard B, Aasbø V, Raeder]. [Admissions and readmissions from a unit of ambulatory surgery. Experiences after 2411 surgical interventions]. Tidsskr Nor Laegeforen. 1996;116:742-5. 
30. Briszi A, Prahs P, Hillenkamp J, Helbig H, Herrmann W. Complication rate and risk factors for intraoperative complications in resident-performed phacoemulsification surgery. Graefes Arch Clin Exp Ophthalmol. 2012;250:1315-20.

31. Hashemi H, Mohammadpour M, Jabbarvand M, Nezamdoost $\mathrm{Z}$, Ghadimi $\mathrm{H}$. Incidence of and risk factors for vitreous loss in resident-performed phacoemulsification surgery. J Cataract Refract Surg. 2013;39:1377-82.

32. Blomquist PH, Morales ME, Tong L, Ahn C. Risk factors for vitreous complications in resident-performed phacoemulsification surgery. J Cataract Refract Surg. 2012;38:208-14.
33. Kothari M, Thomas R, Parikh R, Braganza A, Kuriakose T, Muliyil $J$. The incidence of vitreous loss and visual outcome in patients undergoing cataract surgery in a teaching hospital. Indian J Ophthalmol. 2003;51:45.

34. Rutar T, Porco TC, Naseri A. Risk factors for intraoperative complications in resident-performed phacoemulsification surgery. Ophthalmology. 2009;116:431-6.

35. Woodfield AS, Gower EW, Cassard SD, Ramanthan S. Intraoperative phacoemulsification complication rates of second-and third-year ophthalmology residents: a 5-year comparison. Ophthalmology. 2011;118:954-8. 